\title{
A Retrospective Observational Study of Hypoxic COVID-19 Patients Treated with Immunomodulatory Drugs in a Tertiary Care Hospital
}

\author{
Nilesh Mahale ${ }^{1}$, Prasad Rajhans ${ }^{2}$, Purushotham Godavarthy ${ }^{3}$, Vikram L Narasimhan ${ }^{4}$, Gauri Oak ${ }^{5}$, Srinath Marreddy, \\ Amruta Bedekar ${ }^{7}$, Ujwal Dhundi ${ }^{8}$, Harshwardhan S Pawar ${ }^{9}$, Prasad Akole ${ }^{10}$, Balasaheb Pawar ${ }^{11}$, Bhagyashri Bhurke ${ }^{12}$, \\ Shailaja Chavan ${ }^{13}$, Parikshit Prayag ${ }^{14}$, Bharat Purandare ${ }^{15}$, Pradip Dalvi $^{16}$, Vishnu Telbhare $^{17}$, Prasanna Marudwar ${ }^{18}$, \\ Dnyaneshwar Diwane ${ }^{19}$, Manasi Shahane ${ }^{20}$, Amrita Prayag ${ }^{21}$, Shradha Gugale ${ }^{22}$, Shreyas Bhor ${ }^{23}$, Sameer Jog ${ }^{24}$
}

\begin{abstract}
Objectives: To describe the demographics and evaluate the clinical outcomes of hypoxic coronavirus disease-2019 (COVID-19) patients treated with different immunomodulatory (IM) drugs in a resource-limited setting.

Materials and methods: We conducted a retrospective cohort study of these patients admitted to our hospital between March 22 and May 31 , 2020. Data were abstracted from multiple electronic data sources or patient charts to provide information on patient characteristics, clinical, laboratory variables, and outcomes.

Results: A total of 134 patients met the inclusion criteria and were followed up till June 7, 2020. The median age of the patients was 55.6 years (range $20-89$ years) and $68 \%$ were men. At least one comorbidity was seen in $72 \%$ of the patients with diabetes (44\%) and hypertension (46\%) being the most common. At triage, fever (82\%), shortness of breath (77\%), and cough (61\%) were the most common presenting symptoms. A $\mathrm{PaO}_{2} / \mathrm{FiO}_{2}$ ratio less than 300 was seen in $60 \%$, and $4.5 \%$ required invasive mechanical ventilation within 72 hours of hospital admission. Five immunomodulatory agents (hydroxychloroquine, methylprednisolone, colchicine, etoricoxib, and tocilizumab) were administered in different combinations. Overall, in-hospital mortality was $26.9 \%$, and $32 \%$ required mechanical ventilation. Around $69 \%$ of patients were discharged home. Five variables $\left(\mathrm{SpO}_{2}, \mathrm{PaO}_{2} / \mathrm{FiO}_{2}\right.$ ratio, leukocytosis, lymphopenia, and creatinine) on admission were found to be significant in the patients who died.

Conclusion: Our study provides the characteristics and outcomes of hypoxic COVID-19 patients treated with IM drugs in varied combination. Five independent variables were strong predictors of mortality.

Keywords: Acute respiratory distress syndrome, Coronavirus disease-2019, Immunomodulatory drugs, Resource-limited settings.

Indian Journal of Critical Care Medicine (2020): 10.5005/jp-journals-10071-23599
\end{abstract}

\section{INTRODUCTION}

India reported the first case of coronavirus disease-2019 (COVID19) on January 30, 2020.' The World Health Organization (WHO) declared COVID-19 as pandemic on March 11, 2020, and our hospital admitted the first COVID patient on March 22. Though the exact pathogenesis of severe acute respiratory syndrome-coronavirus-2 (SARS CoV-2) is unknown, various hypotheses have proposed cytokine storm or hyperinflammatory syndrome as probable causes for rapid worsening of the disease. To date, there is no evidence that any potential therapy improves outcomes in patients with COVID$19^{2-4}$ and various antiviral and immunomodulatory (IM) drugs have been repurposed for the treatment of COVID-19.

Currently, there is no published data about baseline characteristics, clinical features, and outcomes from India. Considering the impact the disease has on the public health especially in a resource-limited country like ours, we conducted a retrospective cohort study of the demographics and outcomes of hypoxic COVID-19 patients admitted to our hospital who were treated with various IM agents.

The pharmacology and rationale for use of these IM agents in COVID-19 are depicted in Table 1.
1-4,6,8-12,15-24 Department of Critical Care Medicine, Deenanath Mangeshkar Hospital and Research Center, Pune, Maharashtra, India

${ }^{5}$ Department of Research, Deenanath Mangeshkar Hospital and Research Center, Pune, Maharashtra, India

${ }^{7}$ Department of Anaesthesiology, Deenanath Mangeshkar Hospital and Research Center, Pune, Maharashtra, India

13,14 Department of Infectious Diseases, Deenanath Mangeshkar Hospital and Research Center, Pune, Maharashtra, India

Corresponding Author: Nilesh Mahale, Department of Critical Care Medicine, Deenanath Mangeshkar Hospital and Research Center, Pune, Maharashtra, India, Phone: +91 9082919254, e-mail: nilesh. mahale0@gmail.com

How to cite this article: Mahale N, Rajhans P, Godavarthy P, Narasimhan VL, Oak G, Marreddy S, et al. A Retrospective Observational Study of Hypoxic COVID-19 Patients Treated with Immunomodulatory Drugs in a Tertiary Care Hospital. Indian J Crit Care Med 2020;24(11): 1020-1027.

Source of support: Nil

Conflict of interest: None

(0) The Author(s). 2020 Open Access This article is distributed under the terms of the Creative Commons Attribution 4.0 International License (https://creativecommons. org/licenses/by-nc/4.0/), which permits unrestricted use, distribution, and non-commercial reproduction in any medium, provided you give appropriate credit to the original author(s) and the source, provide a link to the Creative Commons license, and indicate if changes were made. The Creative Commons Public Domain Dedication waiver (http://creativecommons.org/publicdomain/zero/1.0/) applies to the data made available in this article, unless otherwise stated. 


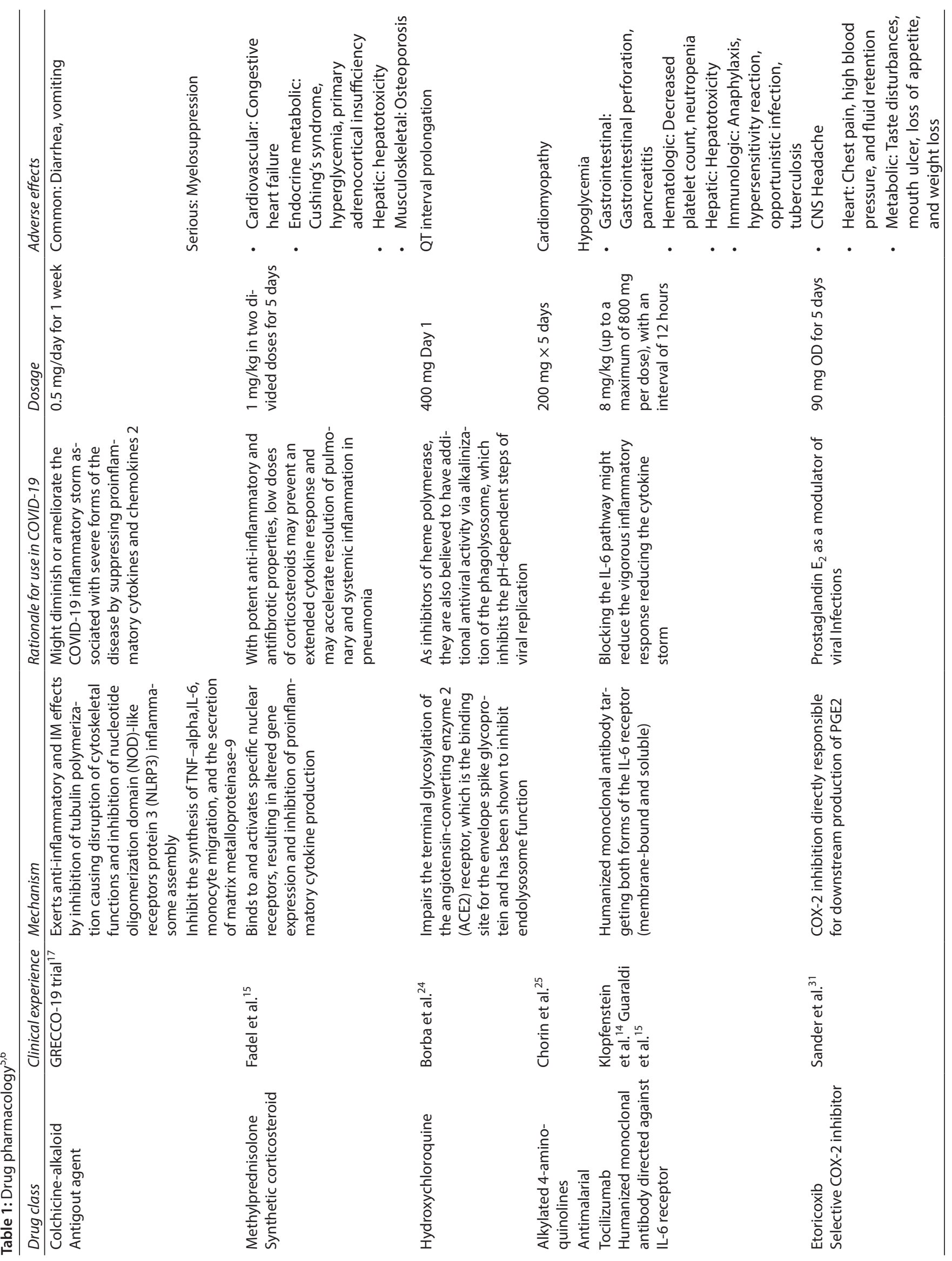




\section{Materials and Methods}

\section{Study Overview}

The study was conducted by the Department of Critical Care Medicine in a tertiary care hospital located in Pune, India. The study was approved by the institutional ethics committee (IHR_2020_APR NM_361) and due to the nature of the retrospective chart review, the need for informed consent from individual patients was waived.

\section{Criteria for Patient Selection}

All patients who presented with symptoms of fever, cough, breathlessness, myalgia or fatigue, and travel history were tested as per the government policy ${ }^{7}$ and admitted to the hospital. Patients who tested positive by RT-PCR for COVID-19, shortness of breath at rest or with exercise (6-minute walk test), and room air saturation less than $94 \%$ requiring oxygen less than $4 \mathrm{~L} /$ minute were admitted to the monitored isolation ward while those requiring oxygen support more than $4 \mathrm{~L}$ /minute were admitted to the intensive care unit (ICU). Five IM drugs, namely tocilizumab, ${ }^{14,15}$ colchicine, ${ }^{17}$ hydroxychloroquine, ${ }^{24,25}$ methylprednisolone, ${ }^{18}$ and etoricoxib ${ }^{31}$ were prescribed in various combinations to these hypoxic patients as per the discretion of the treating physician. The patients were grouped into seven mutually exclusive groups for analysis with a maximum of three drugs in each group for ease in collection of data. Ceftriaxone and azithromycin were given to majority of our patients for the first 3-5 days. Patients were discharged from the ICU and hospital based on a predecided government policy. ${ }^{7}$

\section{Laboratory Confirmation}

Confirmation of COVID-19 was done through real-time reverse transcriptase-polymerase chain reaction (RT-PCR) at National Institute of Virology, Pune, on nasopharyngeal and oropharyngeal samples collected by trained staff as per the government policy.

\section{Inclusion Criteria}

COVID RT-PCR-positive patients aged more than 18 years who required oxygen therapy within 72 hours of their hospital admission.

\section{Exclusion Criteria}

- Patients who were already on steroids or immunosuppressant drugs for any other clinical condition.

- Imminent death within 24 hours of hospital admission (more than two organ failures on admission).

\section{Data Source}

Clinical data pertaining to admitted patients meeting the inclusion criteria were collected between March 22 and May 31, 2020, inclusive of those dates, and the clinical outcomes were monitored till June 7, 2020, the final date of follow-up. Demographics, clinical and laboratory data on admission and the subsequent trends, mode of respiratory support (invasive mechanical ventilation, noninvasive mechanical ventilation, oxygen mask), fraction of inspired oxygen $\left(\mathrm{FiO}_{2}\right)$, arterial partial pressure of oxygen $\left(\mathrm{PaO}_{2}\right), \mathrm{PaO}_{2} / \mathrm{FiO}_{2}$ ratio, and IM agents administered were collected by a team of two senior registrars from the electronic medical records and were entered into a computerized database. The collected data were analyzed and interpreted by two independent intensivists. The clinical team provided clarification on missing or redundant data.

\section{Data Analysis}

Radiological assessment included analysis of chest radiographs and bedside ultrasonography (USG). Laboratory tests were performed as per the clinical needs of the patients at discretion of treating physicians. Electrocardiogram (ECG) and chest radiographs were analyzed by the registrars and confirmed by intensivists. Patients with a baseline QT interval (QTc) more than 500 ms were not administered hydroxychloroquine (HCQ). Data pertaining to coexisting conditions were ascertained from documents/history.

All the authors have checked for the correctness of the data and have reviewed the manuscript and vouch for the correctness, accuracy, and completeness of the data and for the adherence of the study to the protocol submitted.

\section{Study Definitions}

The date of disease onset was defined as the day when the symptoms of fever, cough, breathlessness, myalgia, or fatigue were noticed.

Patients were grouped into mild, moderate, and severe acute respiratory distress syndrome (ARDS) based on calculation of $\mathrm{PaO}_{2} /$ $\mathrm{FiO}_{2}$ ratios $^{8}$ (Table 2).

QT prolongation was considered if QTc was more than $470 \mathrm{~ms}$ in males and $450 \mathrm{~ms}$ in females. ${ }^{9}$ Lymphocytopenia was defined as the absolute lymphocyte count of less than $1000 / \mathrm{mm}^{3}{ }^{10}$

\section{Study Outcomes}

In-hospital mortality, requirement for mechanical ventilation, and discharge or present status of the patients as of June 7, 2020, were recorded separately and also presented on a predefined ordinal scale (Table 3). Length of stay in hospital and ICU were also determined.

\section{Statistical Analysis}

Statistical analysis was carried out with the help of IBM SPSS statistics for Windows, version 23, (IBM Corp., Armonk, NY, USA). The data were analyzed using descriptive statistics. No statistical sample size calculation was performed a priori. Continuous variables were presented as median and interquartile range (IQR), and categorical variables were expressed as counts and percentages. The $\mathrm{Chi}^{2}$ test was used for categorical variables as appropriate. The multivariate regression analysis was carried out to identify independent variables as predictors. All statistical tests were two-tailed, and statistical significance was defined as $p<0.05$. No imputation was made for missing data. As our study population was not derived from random selection, the analysis was not adjusted for multiple comparisons and given the possibility of type I error, all statistics are deemed to be descriptive only.

Table 2: $\mathrm{PaO}_{2} / \mathrm{FiO}_{2}$ ratio

\begin{tabular}{ll}
\hline P/F ratio & Category \\
\hline$>300$ & Normal \\
$\leq 300$ (mild) & Mild \\
$\leq 200$ (moderate) & Moderate \\
$\leq 100$ (severe) & Severe \\
\hline
\end{tabular}

Table 3: Ordinal scale

\begin{tabular}{ll}
\hline 1 & Discharge to home \\
2 & Hospitalized not requiring oxygen but ongoing care for \\
& COVID-related or other medical conditions \\
3 & Hospitalized requiring oxygen \\
4 & Hospitalized requiring noninvasive ventilation or high- \\
& flow oxygen devices \\
6 & Hospitalized on invasive mechanical ventilation \\
\hline
\end{tabular}




\section{Results}

\section{Baseline Characteristics on Admission}

During the study period, a total of 415 confirmed COVID-19 patients were admitted to our hospital. Based on the clinical condition and oxygen requirements, 134 patients who met the inclusion criteria were admitted to monitoring unit or ICU while the rest to the isolation wards.

The median age of the patients in our study was 55.6 years (range 20-89 years) and 68\% were men. Fever was the presenting symptom in $82.1 \%$ of patients while shortness of breath $(77.2 \%)$, cough (61.9\%), myalgia/fatigue (28.4\%), gastrointestinal symptoms (13.4\%), and sore throat (7.5\%) were the other presenting complaints. Approximately $72 \%$ of our study population had at least one comorbidity; diabetes (44\%) and hypertensions (46\%) were the most common comorbidities observed (Table 4B).

Lymphocytopenia was seen in $51.1 \%$ and thrombocytopenia in $13.6 \%$ of patients. Inflammatory markers interleukin 6 , ferritin, and $\mathrm{D}$-dimer were done in selected patients as per the discretion of the treating physician. The number of patients tested and median values are depicted in Table 4C.

About $86 \%$ of the chest radiographs were abnormal with $78.2 \%$ showing involvement of zones $1-4$, while $7.5 \%$ had involvement of zones 1-4 and lobar pneumonia. Bedside lung ultrasound reports were available for 46 patients; $63 \%$ had $B$ lines and $23.9 \%$ had both $B$ lines and subpleural consolidation (Tables 4D and $E$ ).

About $60 \%$ of patients had a $\mathrm{PaO}_{2} / \mathrm{FiO}_{2}$ ratio less than 300 on admission. The $\mathrm{PaO}_{2} / \mathrm{FiO}_{2}$ ratio $\leq 150$ was seen in $50 \%$ of the patients with comorbidities as compared to $31.6 \%$ of patients without comorbidities [ $(p=0.040$, OR 1.2 (95\% Cl 1.0-1.5)] (Table 4F).

Respiratory devices required by these patients (within 72 hours of admission) have been depicted in the Table 4G.

\section{Immunomodulatory Drugs}

- Distribution of IM drugs used (Table 5A): The IM drugs were given to patients in various combinations as per the discretion of the treating physicians. Twenty-three patients could not be placed into any mutually exclusive groups. Hydroxychloroquine ( $n=$ $119)$ and low-dose methylprednisolone $(n=116)$ were given to majority of the patients.

- Outcome (Table 5B): Higher percentage of mortality and ventilator requirements were seen in patient group IV (HCQ+ MPS+ tocilizumab) while patients in group V (only HCQ) had the lowest.

- IM drugs and hospital stay (Table 5C): The mean ICU and hospital stay was longer for patients in group IV (HCQ + MP + tocilizumab) as compared to other groups.

- Interval between symptom onset and initiation of IM drugs (Table 5D): Out of 94 patients who were given IM drugs within 5 days of symptom onset, $63.8 \%$ were discharged home and $28.7 \%$ died. While $77.5 \%$ out of 40 patients who were given IM drugs after 5 days were discharged home and $22.5 \%$ died.

\section{Mortality Statistics}

The mean age of patients who died was $58.8 \pm 12.0$ years with $61 \%$ being men and $80.5 \%$ had more than one associated comorbid condition (Flowchart 1).

The proportion of patients with hypertension was significantly higher among the patients who died (Table 6).
Table 4: Baseline characteristics on admission

\begin{tabular}{llll}
\hline \multicolumn{4}{c}{ A. Demographics } \\
\hline Characteristics & $N$ & $\%$ \\
\hline Men & 91 & 67.9 \\
Age in years, median & 55.6 years & (Range 20-89 years) \\
\hline \multicolumn{4}{c}{ B. Coexisting conditions } \\
\hline Comorbidity & $N$ & $\%$ \\
\hline Diabetes mellitus & 59 & 44 \\
Hypertension & 62 & 46 \\
Ischemic heart disease & 19 & 19 \\
Obesity & 16 & 16 \\
Chronic obstructive lung disease/interstitial lung & 9 & 9 \\
disease & & \\
Chronic kidney disease & 4 & 4 \\
Cancer & 1 & 1 \\
\hline
\end{tabular}

\begin{tabular}{|c|c|c|}
\hline \multicolumn{3}{|c|}{ C. Laboratory } \\
\hline Parameters & $N$ & Median \\
\hline White blood cell count $/ \mathrm{mm}^{3}$ & 132 & $7420(4945-10,810)$ \\
\hline Creatinine in mg\% & 130 & $0.99(0.78-1.58)$ \\
\hline $\begin{array}{l}\text { Nucleotide oligomerization do- } \\
\text { main (NOD)-like receptor (NLR) }\end{array}$ & 134 & $5.93(3.2-9.8)$ \\
\hline IL-6 pg/mL & 24 & $62.8(18.5-100.5)$ \\
\hline C-reactive protein $\mathrm{mg} / \mathrm{L}$ & 105 & $118(56.3-181)$ \\
\hline Ferritin $\mathrm{ng} / \mathrm{mL}$ & 57 & $384.4(135.4-936.4)$ \\
\hline D-dimer ng/mL & 70 & $1015.3(524.5-1527.2)$ \\
\hline \multicolumn{3}{|c|}{ D. Chest X-ray $(n=133)^{*}$} \\
\hline Finding & & $\%$ \\
\hline Normal & & \\
\hline Zone 1-4 & & 78.2 \\
\hline $\begin{array}{l}\text { Zone } 1-4 \text {, lobar } \\
\text { pneumonia }\end{array}$ & & 7 \\
\hline
\end{tabular}

pneumonia

\begin{tabular}{lrl}
\multicolumn{3}{c}{ E. USG Chest $(n=46)$} \\
\hline Normal & 5 & 10.9 \\
B lines & 29 & 63 \\
B lines + subpleural consolidation & 11 & 23.9 \\
Subpleural consolidation & 1 & 2.2 \\
\hline
\end{tabular}

\begin{tabular}{lll}
\multicolumn{3}{c}{ F. Proportion of patients with P/F ratios $(n=116)$} \\
\hline & $\begin{array}{l}\text { Patients on admission } \\
\text { P/F ratio category }\end{array}$ & $\begin{array}{l}\text { Patients with worst } \\
\text { P/F ratio } n(\%)\end{array}$ \\
\hline$\leq 300$ (mild) & $42(31.3)$ & $30(22.4)$ \\
$\leq 200$ (moderate) & $36(26.9)$ & $22(16.4)$ \\
$\leq 100$ (severe) & $18(13.4)$ & $48(35.8)$ \\
$\geq 300$ (normal) & $20(14.9)$ & $16(11.9)$ \\
\hline
\end{tabular}

G. Respiratory assist devices used within 72 hours of admission

\begin{tabular}{lll}
\hline Respiratory assist device & $n$ & (\%) \\
\hline Nasal prongs & 58 & 43.3 \\
$\mathrm{O}_{2}$ mask & 15 & 11.2 \\
Nonrebreathing mask & 40 & 29.8 \\
High-flow nasal oxygen & 15 & 11.2 \\
Invasive mechanical ventilation & 6 & 4.5 \\
\hline
\end{tabular}

*Zones on chest X-ray: Zone 1, apical zone-above the clavicle; Zone 2, between the clavicle and cardiac silhouette; Zone 3, midzone: level of hilar structures; Zone 4, bases 
Table 5: Immunomodulatory drugs

\begin{tabular}{|c|c|c|c|c|c|c|}
\hline \multicolumn{7}{|c|}{ A. Distribution of IM drugs used $(n=134)$} \\
\hline Group & \multicolumn{2}{|l|}{ IM drug group } & \multicolumn{2}{|r|}{$N$} & & $\%$ \\
\hline I & \multicolumn{2}{|l|}{$\mathrm{HCQ}+\mathrm{MP}$} & \multicolumn{2}{|c|}{42} & & 31.3 \\
\hline II & \multicolumn{2}{|l|}{$\mathrm{HCQ}+\mathrm{MP}+$ colchicine } & \multicolumn{2}{|c|}{39} & & 29.1 \\
\hline III & \multicolumn{2}{|l|}{$\mathrm{HCQ}+\mathrm{MP}+$ etoricoxib } & \multicolumn{3}{|c|}{4} & 3.0 \\
\hline IV & \multicolumn{2}{|c|}{$\mathrm{HCQ}+\mathrm{MP}+$ tocilizumab } & \multicolumn{3}{|c|}{5} & 3.7 \\
\hline V & \multicolumn{2}{|l|}{ HCQ } & \multicolumn{3}{|c|}{12} & 9.0 \\
\hline $\mathrm{VI}$ & \multicolumn{2}{|l|}{$M P^{*}$} & \multicolumn{3}{|c|}{9} & 6.7 \\
\hline \multirow[t]{2}{*}{ VII } & \multirow{2}{*}{\multicolumn{2}{|c|}{$\begin{array}{l}\text { Others }{ }^{* *} \\
\text { Total }\end{array}$}} & \multicolumn{3}{|c|}{23} & 17.2 \\
\hline & & & \multicolumn{3}{|c|}{134} & 100 \\
\hline \multicolumn{7}{|c|}{ B. Outcome } \\
\hline & & & \multicolumn{2}{|c|}{ Mortality } & \multicolumn{2}{|c|}{$\begin{array}{c}\text { Requirement } \\
\text { of mechanical } \\
\text { ventilation }\end{array}$} \\
\hline Group & Drug & Given & Died & $\%$ & $\begin{array}{l}\text { Req. } \\
\text { vent }\end{array}$ & $\%$ \\
\hline I & $\mathrm{HCQ}+\mathrm{MP}$ & 42 & 10 & 23.8 & 12 & 28.6 \\
\hline II & $\mathrm{HCQ}+\mathrm{MP}+$ colchicine & 39 & 11 & 28.2 & 15 & 38.5 \\
\hline III & $\mathrm{HCQ}+\mathrm{MP}+$ etoricoxib & 4 & 0 & 0 & 0 & 0 \\
\hline IV & $\begin{array}{l}\mathrm{HCQ}+\mathrm{MP}+ \\
\text { tocilizumab }\end{array}$ & 5 & 2 & 40 & 2 & 40 \\
\hline V & $\mathrm{HCQ}$ & 12 & 2 & 16.7 & 1 & 8.3 \\
\hline VI & $M P^{*}$ & 9 & 3 & 33.3 & 3 & 33.3 \\
\hline VII & Others ${ }^{* *}$ & 23 & 8 & 34.8 & 7 & 30.4 \\
\hline
\end{tabular}

\begin{tabular}{|c|c|c|c|c|c|}
\hline \multicolumn{2}{|c|}{ Distribution of IM drugs } & \multicolumn{2}{|c|}{$\begin{array}{c}\text { Mean ICU stay ( } n \\
=65)\end{array}$} & \multicolumn{2}{|c|}{$\begin{array}{l}\text { Mean hospital } \\
\text { stay }(n=134)\end{array}$} \\
\hline Group & IMdrug & $n$ & Mean & $n$ & Mean \\
\hline $\mathrm{I}$ & $\mathrm{HCQ}+\mathrm{MP}$ & 16 & 3.50 & 42 & 10.67 \\
\hline ॥ & $\begin{array}{l}\mathrm{HCQ}+\mathrm{MP}+ \\
\text { colchicine }\end{array}$ & 31 & 6.39 & 39 & 12.77 \\
\hline III & $\begin{array}{l}\mathrm{HCQ}+\mathrm{MP}+ \\
\text { etoricoxib }\end{array}$ & 0 & 0 & 4 & 11.50 \\
\hline IV & $\begin{array}{l}\mathrm{HCQ}+\mathrm{MP}+ \\
\text { tocilizumab }\end{array}$ & 2 & 15.00 & 5 & 15.60 \\
\hline V & $\mathrm{HCQ}$ & 4 & 3.25 & 12 & 10.17 \\
\hline $\mathrm{Vl}$ & $M P^{*}$ & 4 & 2.50 & 9 & 9.00 \\
\hline VII & Others** & 12 & 6.92 & 23 & 14.52 \\
\hline
\end{tabular}

D. Interval between symptom onset to IM drug initiation

\begin{tabular}{lcc}
\hline Parameter & $\begin{array}{l}\text { Interval }<5 \text { days } \\
(n=94)\end{array}$ & $\begin{array}{l}\text { Interval } \geq 5 \text { days } \\
(n=40)\end{array}$ \\
\hline $\begin{array}{l}\text { Ordinal scale } \\
\text { Well and discharged home }\end{array}$ & $60(63.8)$ & $31(77.5)$ \\
$\begin{array}{l}\text { Hospitalized, not requiring } \mathrm{O}_{2} \\
\text { Hospitalized, requiring NIV or }\end{array}$ & $2(2.1)$ & $0(0)$ \\
$\begin{array}{l}\text { high-flow } \mathrm{O}_{2} \text { devices } \\
\text { Hospitalized, requiring invasive } \\
\text { mechanical ventilation }\end{array}$ & $4(4.3)$ & $0(0)$ \\
\begin{tabular}{l} 
Death \\
\hline
\end{tabular} & $27(28.7)$ & $0(0)$ \\
\hline
\end{tabular}

$\mathrm{HCQ}$, hydroxychloroquine; ICU, intensive care unit; $\mathrm{MP}$, methylprednisolone; NIV, noninvasive ventilation

* Low dose

${ }^{* *}$ Contains drug combinations not present in any of the predefined groups
Table 6: Mortality statistics

\begin{tabular}{lc}
\hline Parameter & Died $n(\%)$ \\
\hline Coexisting conditions & \\
Diabetes mellitus & $17(47.2)$ \\
Hypertension & $23(63.9)$ \\
Ischemic heart disease & $6(16.7)$ \\
Obesity & $7(19.4)$ \\
Respiratory parameters & \\
P/F ratio <200 & $34(94.4)$ \\
Invasive ventilation & $36(100 \%)$ \\
Laboratory parameters & \\
Normal lymphocyte count & $12(33.3)$ \\
Highest s. creatinine $>1.2$ mg\% & $28(77.8)$ \\
Thrombocytopenia & $5(13.9)$ \\
Total & $36(100)$ \\
\hline
\end{tabular}

Flowchart 1: Patient inclusion and disposition on admission

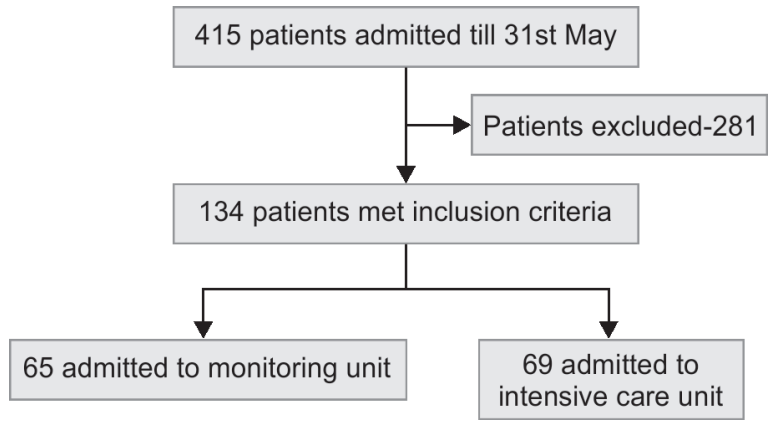

A multivariate regression analysis was carried out based on the available independent variables from clinical and laboratory data, to identify factors predicting mortality. A model was constructed using significant predictors from both groups together (Table 7).

It was found that $\mathrm{SpO}_{2}<80 \%$, respiratory rate $>22 /$ minute.

$\mathrm{PaO}_{2} / \mathrm{FiO}_{2}<200$, white blood cell count $>12,000 / \mathrm{mm}^{3}$, absolute lymphocyte count $<1000 / \mathrm{mm}^{3}$, and the highest serum creatinine $>1.2 \mathrm{mg} \%$ were significant predictors.

The overall model fit was $R^{2}=46.8 \%$.

\section{Outcomes and Adverse Events}

None of the 134 patients were lost to follow-up during the study. A primary endpoint (discharge or death) occurred in $95.6 \%$ of patients. About $68.7 \%$ of patients were discharged home, while $26.9 \%$ died and rest were still at hospital undergoing various stages of treatment till the time of analysis of data. The cause of death is depicted in Table 8B. About 50\% of patients had hyperglycemia, $20.1 \%$ had QTC prolongation, and secondary bacterial infection was seen in $13.4 \%$ of patients while $40.3 \%$ patients had no known adverse events documented during the course of study (Table $8 \mathrm{C}$ ).

\section{Discussion}

This retrospective study would be to our knowledge the first study in India and among other resource-limited countries that presents a wide spectrum of descriptive and analytical data of hypoxic COVID-19 patients treated with a varied combination of IM drugs. During the course of our study, we noted that five variables among the clinical and laboratory parameters were found to be significant 
Table 7: Significant predictors

\begin{tabular}{|c|c|c|c|c|c|}
\hline \multicolumn{6}{|c|}{ Multivariate regression analysis } \\
\hline \multirow[b]{2}{*}{ Model } & \multicolumn{2}{|c|}{$\begin{array}{c}\text { Unstandardized } \\
\text { coefficients }\end{array}$} & \multirow{2}{*}{$\begin{array}{l}\text { Standardized } \\
\text { coefficients } \\
\text { Beta }\end{array}$} & \multirow[b]{2}{*}{$t$} & \multirow[b]{2}{*}{$p$ value } \\
\hline & $B$ & Std. error & & & \\
\hline (Constant) & -0.092 & 0.205 & & -0.450 & 0.654 \\
\hline Highest S. creatinine, mg\% & 0.315 & 0.068 & 0.342 & 4.628 & 0.000 \\
\hline $\mathrm{SpO}_{2}<80 \%$ & 0.278 & 0.080 & 0.269 & 3.455 & 0.001 \\
\hline $\mathrm{PF}$ ratio $<200$ & 0.164 & 0.072 & 0.179 & 2.272 & 0.025 \\
\hline Absolute lymphocyte count $<1,000 / \mathrm{mm}^{3}$ & 0.163 & 0.065 & 0.181 & 2.518 & 0.013 \\
\hline WBC more than $12,000 / \mathrm{mm}^{3}$ & 0.195 & 0.087 & 0.171 & 2.247 & 0.027 \\
\hline
\end{tabular}

Dependent variable: mortality

Table 8: Outcome data

\begin{tabular}{|c|c|c|}
\hline \multicolumn{3}{|c|}{ A. Outcome ordinal scale (at the time of going to analysis) } \\
\hline Scale order & Ordinal scale description & Patients $n(\%)$ \\
\hline 1 & Well and discharged home & $91(68.7)$ \\
\hline 2 & Hospitalized, not requiring $\mathrm{O}_{2}$ & $2(1.5)$ \\
\hline 3 & $\begin{array}{l}\text { Hospitalized, requiring NIV or high- } \\
\text { flow } \mathrm{O}_{2} \text { devices }\end{array}$ & $1(0.7)$ \\
\hline 4 & $\begin{array}{l}\text { Hospitalized, requiring invasive } \\
\text { mechanical ventilation }\end{array}$ & $4(3)$ \\
\hline 5 & Death & $36(26.9)$ \\
\hline \multicolumn{3}{|c|}{ B. Causes of death $(n=36)$} \\
\hline \multicolumn{2}{|c|}{ Cause of death } & $n(\%)$ \\
\hline \multicolumn{2}{|l|}{ Respiratory } & $19(52.8)$ \\
\hline \multicolumn{2}{|c|}{ Multiorgan failure + sepsis } & $15(41.7)$ \\
\hline \multicolumn{2}{|l|}{ Cardiac } & $2(5.6)$ \\
\hline \multicolumn{3}{|c|}{$34(94.4 \%)$ died in the intensive care unit } \\
\hline
\end{tabular}

\begin{tabular}{lc}
\multicolumn{2}{c}{ C. Adverse events $(n=134)$} \\
\hline Adverse event & $n(\%)$ \\
\hline High sugars & $67(50)$ \\
QTc prolongation & $27(20.1)$ \\
Acute coronary syndrome & $5(3.7)$ \\
Secondary bacterial infection & $18(13.4)$ \\
Shock & $20(14.9)$ \\
None & $54(40.3)$ \\
\hline
\end{tabular}

predictors of mortality. No single IM drug or in combination with others was associated with outcome.

Immunomodulation remains to be the mainstay of treatment based on our previous experiences with SARS and H1N1 pandemics in the absence of any effective direct antiviral drug therapy. ${ }^{11,12}$ Siddiqi et al. ${ }^{13}$ proposed a three-stage classification of COVID-19 illness and suggested starting of anti-inflammatory therapies such as steroids from stage IIB when hypoxia develops. Majority of our patients received hydroxychloroquine and methyl prednisolone. Owing to the nonuniformity in groups of IM drugs administered and lack of control groups, only descriptive analysis was possible in our study. However, we noted a longer ICU/hospital stay, higher percentage of mortality, and ventilator requirements in patients receiving a combination of tocilizumab along with HCQ and methyl prednisolone. This is contrary to the results from case control studies by Klopfenstein et al. ${ }^{14}$ and Guaraldi et al. ${ }^{15}$ that showed significantly less percentage of mortality in the tocilizumab group. The observations of our study may be explained by the fact that tocilizumab was administered to a very small proportion of patients. On the other hand, the length of the hospital/ICU stay in our patients is comparable to study by Tariq Kewan et al., ${ }^{16}$ which showed longer duration of hospital stay in the tocilizumab group.

In a study conducted by Spyridon G. Deftereos et al., ${ }^{17}$ no statistically significant outcomes were observed in participants who received colchicine along with $\mathrm{HCQ}$, azithromycin, and tocilizumab.

Two recent studies by Fadel et al. ${ }^{18}$ and Fernández-Cruz et al. ${ }^{19}$ reported a beneficial effect on mortality in patients treated with steroids in early phase where the interval between symptom onset to IM drug initiation was a median value of 8 and 10 days, respectively. Most of our patients were initiated with IM drugs before 5 days of onset of illness, which is much earlier when compared to the above studies.

More than half of our patients were admitted to the ICU. About $32 \%(n=43)$ of our patients required mechanical ventilation during the hospital stay. This percentage is higher when compared to the earliest statistics from Wuhan, China ${ }^{20}(16 \%)$ and lower when compared to Lombardy, Italy ${ }^{21}(88 \%)$ and fairly comparable to other studies from Wuhan, China (30\%). ${ }^{22}$

Considering the fact that $96 \%$ of our patients had attained the primary endpoints, the mortality rate in our study was very low, which is similar to most of the statistics from New York, ${ }^{23}$ Lombardy, ${ }^{21}$ and Wuhan. ${ }^{20}$ Our patients were much younger and the proportion of hypertensives was significantly higher in those who died. In-hospital mortality rate of $26.9 \%$ and a higher mortality $(83.7 \%)$ in patients who were mechanically ventilated were comparable to results from different regions of the world. It is difficult to compare mortality rates between studies because the outcomes can be affected by healthcare systems, resources, patient demographics, and prevalence of comorbidities. Mortality rates might be higher in studies conducted over long-term or at a different epidemiological stage.

Among adverse events, our incidence of QTc prolongation (20\%) was higher than other studies where HCQ was used. This could be because of our threshold of QT prolongation being $>450$ $\mathrm{ms}$ in males and $\mathbf{4 7 0} \mathrm{ms}$ in females as compared to other studies and also the fact that most of our patients were coadministered azithromycin.

A study by Borba et al. ${ }^{24}$ in patients suffering from SARI COVID-19, looking at high-dose vs. low-dose HCQ therapy found QT prolongation in $18 \%$ of high-dose compared to $11 \%$ of lowdose group pointing toward dose-related toxicity. Chorin et al. ${ }^{25}$ 
showed that in 84 patients treated with hydroxychloroquine and azithromycin, QTc prolonged maximally from baseline in $11 \%$ of patients, representing the high-risk group for arrhythmia.

The incidence of hyperglycemia (50\%) and clinically significant secondary bacterial infections requiring escalation of antibiotics was comparable with other studies. ${ }^{26}$

Recent studies ${ }^{27-31}$ have reported an association between age, high WBC counts, and absolute neutrophil value with low lymphocyte count (neutrophil-lymphocyte ratio) and worse outcomes.

In our study, we found that the following five variables $\left(\mathrm{SpO}_{2}\right.$ $<80 \%$, RR $>22 /$ minute, $\mathrm{PaO}_{2} / \mathrm{FiO}_{2}<200, \mathrm{WBC}>12,000 / \mathrm{mm}^{3}$, ALC $<1000 / \mathrm{mm}^{3}$, sr. creatinine $>1.2 \mathrm{mg} \%$ ) were found to be significant predictors of mortality in our patients. Even though these variables have not been validated as a scoring system, the need of the time is to develop a scoring system based on ubiquitous clinical findings and laboratory biomarkers for early triage and disposition especially in resource-limited settings.

\section{Limitations}

Our study has several limitations. First, this was a retrospective observational study with all its inherited biases. Second, the data were collected from electronic medical health record database, thereby precluding detailed information about the patients demographics and baseline medications. Third, the nonuniformity in the distribution of the IM agents, limited investigations being done because of cost constraints, high heterogeneity observed, due to the participants' inclusion criteria as well as by the studies design making the data redundant for comparative analysis. Fourth, as the follow-up time of our study was relatively short compared to the course of the disease, it could change the outcome variables studied.

\section{Strengths}

Our study would be one of its kind comparing groups of IM drugs and their outcomes in resource-limited settings. It also provides a wide spectrum of demographic data of critical COVID-19 patients from our country and their outcomes in a tertiary level hospital in India.

\section{Implications for Future Research}

Larger trials with a more robust study design, randomized control trials comparing the different IM agents in regards to important clinical outcome variables. Construction and validation of outcome predictor scores based on easily available clinical and laboratory variables to guide the clinicians for better allocation of the scarce medical resources especially in resource-limited settings.

\section{Conclusion}

In our study of critically ill hypoxic COVID-19 patients, five different IM agents were used in varied combinations. The requirement of mechanical ventilation was seen in $32 \%$, in-hospital mortality rate was $26.9 \%$, and a higher mortality of $83.7 \%$ among the mechanically ventilated patients. Five variables among the clinical and laboratory parameters were found to be significant predictors of mortality.

\section{References}

1. Andrews M, Areekal B, Rajesh K, Krishnan J, Suryakala R, Krishnan $B$, et al. First confirmed case of COVID-19 infection in India: a case report. Indian J Med Res 2020;151(5):490-492. DOI: 10.4103/ijmr. IJMR_2131_20.

2. Ruan Q, Yang K, Wang W, Jiang L, Song J. Clinical predictors of mortality due to COVID-19 based on an analysis of data of 150 patients from Wuhan, China. Intensive Care Med 2020;46(5):846-848. DOI: 10.1007/s00134-020-05991-x.

3. Wu C, Chen X, Cai Y, Xia J, Zhou X, Xu S, et al. Risk factors associated with acute respiratory distress syndrome and death in patients with coronavirus disease 2019 pneumonia in Wuhan, China. JAMA Int Med 2020;180(7):934. DOI: 10.1001/jamainternmed.2020.0994.

4. Yang X, Yu Y, Xu J, Shu H, Xia J, Liu H, et al. Clinical course and outcomes of critically ill patients with SARS-CoV-2 pneumonia in Wuhan, China: a single-centered, retrospective, observational study. Lancet Respirat Med 2020;8(5):475-481. DOI: 10.1016/S2213-2600(20)30079-5.

5. Tufan A, Avanoğlu Güler A, Matucci-Cerinic M. COVID-19, immune system response, hyperinflammation and repurposing antirheumatic drugs. Turk J Med Sci 2020;50(SI-1):620-632. DOI: 10.3906/sag-2004168.

6. Salvi R, Patankar P. Emerging pharmacotherapies for COVID19. Biomed Pharmacother. 2020;128:110267. DOI: 10.1016/j. biopha.2020.110267.

7. Huang I, Pranata R. Lymphopenia in severe coronavirus disease-2019 (COVID-19): systematic review and meta-analysis. J Intensive Care 2020;8(1):36. DOI: 10.1186/s40560-020-00453-4.

8. Alijotas-Reig J, Esteve-Valverde E, Belizna C, et al. Immunomodulatory therapy for the management of severe COVID-19. Beyond the anti-viral therapy: a comprehensive review. Autoimmun Rev 2020;19(7):102569. DOI: 10.1016/j.autrev.2020.102569.

9. Grasselli G, Zangrillo A, Zanella A, Antonelli M, Cabrini L, Castelli A, et al. Baseline characteristics and outcomes of 1591 patients infected with SARS-CoV-2 admitted to ICUs of the Lombardy region, Italy. JAMA 2020;323(16):1574. DOI: 10.1001/jama.2020.5394.

10. Huang $C$, Wang $Y$, Li $X$, Ren $L$, Zhao J, Hu Y, et al. Clinical features of patients infected with 2019 novel coronavirus in Wuhan, China. Lancet 2020;395(10223):497-506. DOI: 10.1016/S0140-6736(20) 30183-5.

11. [Internet].Mohfw.gov.in.2020[cited 13 July2020].Availablefrom:https:// www.mohfw.gov.in/pdf/ICMRrevisedtestingstrategyforCOVID.pdf.

12. ARDS Definition Task Force, Ranieri VM, Rubenfeld GD, Thompson BT, Ferguson ND, Caldwell E, et al. Acute respiratory distress syndrome: the Berlin definition. JAMA 2012;307(23):2526-2533. DOI: 10.1001/ jama.2012.5669.

13. Siddiqi H, Mehra M. COVID-19 illness in native and immunosuppressed states: a clinical-therapeutic staging proposal. J Heart Lung Transplantat 2020;39(5):405-407. DOI: 10.1016/j.healun.2020.03.012.

14. Klopfenstein T, Zayet S, Lohse A, Balblanc JC, Badie J, Royer PY, et al. Tocilizumab therapy reduced intensive care unit admissions and/or mortality in COVID-19 patients. Médecine et Maladies Infectieuses 2020(5). DOI: 10.1016/j.medmal.2020.05.001.

15. Guaraldi G, Meschiari M, Cozzi-Lepri A, Milic J, Tonelli R, Menozzi M, et al. Tocilizumab in patients with severe COVID-19: a retrospective cohort study. The lancet. Rheumatology 2020(8). DOI: 10.1016/S26659913(20)30173-9.

16. Kewan T, Covut F, Al-Jaghbeer MJ, Rose L, Gopalakrishna KV, Akbik B. Tocilizumab for treatment of patients with severe COVID-19: a retrospective cohort study. E Clin Med 2020;. 100418. DOI: 10.1016/j. eclinm.2020.100418.

17. Deftereos SG, Giannopoulos G, Vrachatis DA, Siasos GD, Giotaki SG, Gargalianos P, et al. Effect of colchicine vs standard care on cardiac and inflammatory biomarkers and clinical outcomes in patients hospitalized with coronavirus disease 2019. JAMA Network Open 2020;3(6):e2013136. DOI: 10.1001/jamanetworkopen.2020.13136.

18. Fadel R, Morrison AR, Vahia A, Smith ZR, Chaudhry Z, Bhargava P, et al., Henry Ford COVID-19 Management Task Force, Oxford University Press for the Infectious Diseases Society of America 2020.

19. Fernández Cruz A, Ruiz-Antorán B, Muñoz Gómez A, Sancho López A, Mills Sánchez P, Centeno-Soto GA, et al. Impact of glucocorticoid 
treatment in SARS-CoV-2 infection mortality: a retrospective controlled cohort study. Antimicrob Agents Chemother 2020(9). DOI: 10.1128/aac.01168-20.

20. Sander W, O'Neill H, Pohl C. Prostaglandin E2 as a modulator of viral infections. Front Physiol 2017. 8. DOI: 10.3389/fphys.2017.00089.

21. Vetter V. Clues or miscues? Circulation 2007;115(20):2595-2598. DOI: 10.1161/CIRCULATIONAHA.107.700195.

22. Felsenstein S, Herbert J, McNamara P, Hedrich C. COVID-19: immunology and treatment options. Clin Immunol 2020;215:108448. DOI: 10.1016/j.clim.2020.108448.

23. Zhou F, Yu T, Du R, Fan G, Liu Y, Liu Z, et al. Clinical course and risk factors for mortality of adult inpatients with COVID-19 in Wuhan, China: a retrospective cohort study. Lancet 2020;395(10229):10541062. DOI: 10.1016/S0140-6736(20)30566-3.

24. Borba MGS, Val FFA, Sampaio VS, Alexandre MAA, Melo GC, Brito M, et al. Effect of high vs low doses of chloroquine diphosphate as adjunctive therapy for patients hospitalized with severe acute respiratory syndrome coronavirus 2 (SARS-CoV-2) infection. JAMA Network Open 2020;3(4):e208857. DOI: 10.1001/jamanetworkopen.2020.8857.

25. Chorin E, Dai M, Shulman E, Wadhwani L, Bar-Cohen R, Barbhaiya C, et al. The QT interval in patients with COVID-19 treated with hydroxychloroquine and azithromycin. Nat Med 2020;26(6):808-809. DOI: 10.1038/s41591-020-0888-2.
26. Richardson S, Hirsch JS, Narasimhan M, Crawford JM, McGinn T, Davidson KW, et al. Presenting characteristics, comorbidities, and outcomes among 5700 patients hospitalized with COVID-19 in the New York city area. JAMA 2020;323(20):2052. DOI: 10.1001/ jama.2020.6775.

27. Li X, Xu S, Yu M, Wang K, Tao Y, Zhou Y, et al. Risk factors for severity and mortality in adult COVID-19 inpatients in Wuhan. J Aller Clin Immunol 2020;146(1):110-118. DOI: 10.1016/j.jaci.2020. 04.006.

28. Zhang C, Qin L, Li K, Wang Q, Zhao Y, Xu B, et al. A novel scoring system for prediction of disease severity in COVID-19. Front Cell Infect Microbiol 2020;10:318. DOI: 10.3389/fcimb.2020.00318.

29. Gong J, Ou J, Qiu X, Jie Y, Chen Y, Yuan L, et al. A tool for early prediction of severe coronavirus disease 2019 (COVID-19): a multicenter study using the risk nomogram in Wuhan and Guangdong. China Clin Infect Dis 2020(15):ciaa443. DOI: 10.1093/cid/ciaa443.

30. Wang L, He W, Yu X, Hu D, Bao M, Liu H, et al. Coronavirus disease 2019 in elderly patients: characteristics and prognostic factors based on 4-week follow-up. J Infect 2020;80(6):639-645. DOI: 10.1016/j. jinf.2020.03.01.

31. Yang A, Liu J, Tao W, Li H. The diagnostic and predictive role of NLR, d-NLR and PLR in COVID-19 patients. Int Immunopharmacol 2020;84:106504. DOI: 10.1016/j.intimp.2020.106504. 